\title{
Erratum to "On some fixed points of $\alpha-\psi$ contractive map- pings with rational expressions, J. Nonlinear Sci. Appl., 10 (2017), 1569 - 1581"
}

\section{Erdal Karapınar}

Department of Mathematics, Atilim University 06836, Incek, Ankara, Turkey.

Communicated by M. Bohner

\begin{abstract}
The aim of this note is to correct the affiliation of the authors in [E. Karapınar, A. Dehici, N. Redjel, J. Nonlinear Sci. Appl., 10 (2017), 1569-1581]. We shall also extend the main result of this paper further.
\end{abstract}

Keywords: Complete metric space, (c)-comparison function, fixed point, $\alpha$-admissible mapping, cyclic mapping. 2010 MSC: 46T99, 47H10, 54H25.

(C)2018 All rights reserved.

\section{Introduction and Preliminaries}

The main aim of this note is to correct the affiliation of the first author in [2]. On the other hand, by getting a chance for putting a note on [2], we shall give a more generalized version of the main results in [2]. For this purpose, we shall use the notion of simulation function:

Definition 1.1 ([3]). A simulation function is a mapping $\zeta:[0, \infty) \times[0, \infty) \rightarrow \mathbb{R}$ satisfying the following conditions:

$\left(\zeta_{1}\right) \zeta(t, s)<s-t$ for all $t, s>0$;

$\left(\zeta_{2}\right)$ if $\left\{t_{n}\right\},\left\{s_{n}\right\}$ are sequences in $(0, \infty)$ such that $\lim _{n \rightarrow \infty} t_{n}=\lim _{n \rightarrow \infty} s_{n}>0$, then

$$
\limsup _{n \rightarrow \infty} \zeta\left(t_{n}, s_{n}\right)<0 .
$$

Notice that in [3] there was a superfluous condition $\zeta(0,0)=0$. Let $z$ denote the family of all simulation functions $\zeta:[0, \infty) \times[0, \infty) \rightarrow \mathbb{R}$. Due to the axiom $\left(\zeta_{1}\right)$, we have

$$
\zeta(t, t)<0 \text { for all } t>0 .
$$

Email address: erdal.karapinar@atilim.edu.tr (Erdal Karapınar)

doi: $10.22436 /$ jnsa.011.03.10

Received: 2017-12-15 Revised: 2018-01-20 Accepted: 2018-01-21 
Example 1.2 (See e.g. $[1,3,4]$ ). We define the mappings $\zeta_{i}:[0, \infty) \times[0, \infty) \rightarrow \mathbb{R}$, for $i=1,2,3$, as follows:

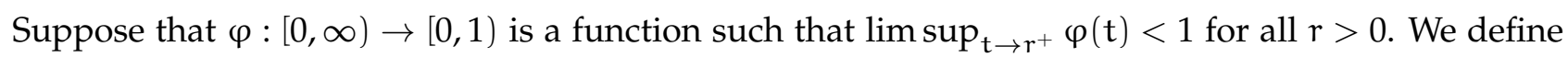

$$
\zeta_{1}(t, s)=s \varphi(s)-t \quad \text { for all } s, t \in[0, \infty) .
$$

Let $\eta:[0, \infty) \rightarrow[0, \infty)$ be an upper semi-continuous mapping such that $\eta(t)<t$ for all $t>0$ and $\eta(0)=0$. Then, we construct

$$
\zeta_{2}(t, s)=\eta(s)-t \quad \text { for all } s, t \in[0, \infty) .
$$

If $\phi:[0, \infty) \rightarrow[0, \infty)$ is a function such that $\int_{0}^{\varepsilon} \phi(u) d u$ exists and $\int_{0}^{\varepsilon} \phi(u) d u>\varepsilon$, for each $\varepsilon>0$, then we state

$$
\zeta_{3}(t, s)=s-\int_{0}^{t} \phi(u) d u \quad \text { for all } s, t \in[0, \infty)
$$

Clearly, each function $\zeta_{i}(i=1,2,3)$ is a simulation function.

\section{Simulation results}

In this section, we shall generalize the main result in [2]. We refer to [2], for all used notions and notations here.

We start this section by introducing the concept of $\alpha-\psi-K$ mappings of $\zeta$ type.

Definition 2.1. Let $(X, d)$ be a metric space and $f: X \longrightarrow X$ be a given mapping and $\zeta \in Z$. We say that $f$ is an $\alpha-\psi-\mathrm{K}$ mapping of $\zeta$ type if there exist two functions $\alpha: X \times X \longrightarrow[0, \infty)$ and $\psi \in \Psi$ such that

$$
\zeta(\alpha(x, y) d(f(x), f(y)), \psi(K(x, y))) \geqslant 0
$$

for all $x, y \in X, x \neq y$, where

$$
\begin{aligned}
K(x, y)=\max & \left\{d(x, y), \frac{d(x, f(x))+d(y, f(y))}{2}, \frac{d(x, f(y))+d(y, f(x))}{2},\right. \\
& \left.\frac{d(x, f(x)) d(y, f(y))}{d(x, y)}, \frac{d(y, f(y))[1+d(x, f(x))]}{[1+d(x, y)]}\right\} .
\end{aligned}
$$

Theorem 2.2. Let $(X, d)$ be a complete metric space. Suppose that $\mathrm{f}: \mathrm{X} \longrightarrow \mathrm{X}$ is an $\alpha-\psi-\mathrm{K}$ mapping of $\zeta$ type satisfying the following conditions:

(i) f is $\alpha$-admissible;

(ii) there exists $x_{0} \in X$ such that $\alpha\left(x_{0}, f\left(x_{0}\right)\right) \geqslant 1$;

(iii) $f$ is continuous.

Then there exists $u \in X$ such that $f(u)=u$.

Sketch of the Proof.

$$
0 \leqslant \zeta(\alpha(x, y) d(f(x), f(y)), \psi(K(x, y)))<\psi(K(x, y))-\alpha(x, y) d(f(x), f(y)),
$$

which yields that

$$
\alpha(x, y) d(f(x), f(y))<\psi(K(x, y)) .
$$

Verbatim of the proof of the main theorem in [2], we complete the proof. 


\section{Correction of the affiliation in [2]}

The affiliation of the first author, Erdal Karapinar, in the recently published paper [2] should be "Department of Mathematics, Atilim University 06836, Incek, Ankara, Turkey".

\section{Acknowledgment}

The author is grateful to the editor for his indispensable help.

\section{References}

[1] H. H. Alsulami, E. Karapınar, F. Khojasteh, A.-F. Roldán-López-de-Hierro, A proposal to the study of contractions in quasi-metric spaces, Discrete Dyn. Nat. Soc., 2014 (2014), 10 pages. 1.2

[2] E. Karapınar, A. Dehici, N. Redjel, On some fixed points of $\alpha-\psi$ contractive mappings with rational expressions, J. Nonlinear Sci. Appl., 10 (2017), 1569-1581. 1, 2, 2, 3

[3] F. Khojasteh, S. Shukla, S. Radenović, A new approach to the study of fixed point theorems via simulation functions, Filomat, 29 (2015), 1189-1194. 1.1, 1.1, 1.2

[4] A.-F. Roldán-López-de-Hierro, E. Karapınar, C. Roldán-López-de-Hierro, J. Martínez-Moreno, Coincidence point theorems on metric spaces via simulation functions, J. Comput. Appl. Math., 275 (2015), 345-355. 1.2 